\title{
Male Sexualisation in Music Videos: A Critical Analysis under Nussbaum's Perspective of Objectification
}

\author{
Sana Ali ${ }^{1}$, Ayesha Qamar ${ }^{2}$ \\ Allama Iqbal Open University Islamabad ${ }^{1}$, \\ Fatima Jinnah Women University, The Mall Rawalpindi ${ }^{2}$ \\ Email: sana_leo1990@hotmail.com ${ }^{1}$, ayeshaqamar@fjwu.edu.pk ${ }^{2}$ \\ DOI $<$ 10.26821/IJSRC.8.2.2020.8208>
}

\begin{abstract}
Sexual objectification is profoundly practised in media. It leads to recognizing sexual behaviours and psychological distress among individuals. This study is aimed to investigate the male objectification in music videos under "Objectification" as a theoretical perspective proposed by Martha Nussbaum and Rae Langton. To investigate objectification, the researchers selected a sample of 100 music videos featured in 2018's Billboard Charts Songs. By using direct content analysis method, the researchers gathered data from the selected music content. Results unveiled that $n=77$ or $79.3 \%$ of the videos contained objectified portrayals of men in them. Moreover, out of two selected music genres, Hiphop contained comparatively higher $(n=46$ or $59.7 \%$ ) of objectified portrayals than Pop music videos ( $\mathrm{n}-31$ or $40.2 \%)$. Therefore, the study recommends that male objectification is equally imperative and needs to be addressed. As representing the male body as sexually pleasant, lacking integrity and to satisfy female gaze is as crucial as that of women.
\end{abstract}

Keywords: Male Objectification; Sexualized portrayals; Psychological Distress; Music Videos; Dehumanization; Sexualized Behaviours

\section{INTRODUCTION}

Entertainment is an important part of the media and plays "uses and gratification" role in mass media content. Video games, serials, music and other media content help to improve cognitive health.
Due to the mood management aspect, entertainment also leads to improved brain development (Goldstein, 2017).Media industry resorts to entertainment besides educating and informing people as people are not willing to accept boredom in solely educational or informational programs. It is suitable for a message to contain an entertainment factor that can help to pass information efficiently(Brown \& Singhal, 1993). Also affirmed by (Dinu, 2016) as he considered entertainment comparatively more prominent than "just information". In media, some particular entertainment stories gain much more attention than the other informative ones. That is why people are more aware of their favourite media content rather than educational or news reports. Especially, music serves as an important part of mass media culture. It is not merely a source of entertainment also serves public education roles (Chopyak, 1987). According to (Celasİn, 2013), music helps people to express themselves, to interact with others and also to shape their opinion inform of the others. Today, there is hardly anyone who does not prefer music for entertainment purpose. Therefore, it is an aesthetical and sociological perspective of mass media content. The role of music in media industry is briskly gaining more significance. It is an art to entertain and to get entertained (Rager \& Rager, 2008). However, music has new renditions overtime, introducing diverse genres to entertain the diverse audience. These genres help to divide the music into different classes and help the musicians to make their own unique identity (Silver, Lee, \& Childress, 2016). Moreover, songs with music videos gain greater attention. According to (Starej, 
Volume 8 Issue 2 February 2020

2017), the illustration is an essential component of music content in which the singers tend to perform on his song. Arguably, the trend of music videos have always been into transitioning process but they are a fundamental part of the music industry today. It is because there is a strong structural relationship between music and music video. Video has cultural determined meanings and when represented with music, these meanings have stronger impacts. These videos are narrative in nature and thus receive greater attention and appreciation from the audience (Bjornberg, 2011). Several studies have also reported that due to variety of ideas, sentiments and feelings music videos are high in demand (Vernallis, 1998) analyzed the music video of a popular song "cherish" by Madonna. According to the researcher, the illustration not only helped the newly introduced artist to gain recognition but also contained aesthetic components. It had refined video editing skills and effects that made it more eye-catching for the spectators. Thus, "Cherish" gain much for appreciation and recognition from all over the world.

In the meantime, this important form of media content also faces backlash from the critiques. An intense discussion about sexual objectification in music is an ongoing phenomenon (Karsay \& Matthes, 2016). This is because appealing through sexualisation is an important theme of mass media content. Especially, sexualisation is a common practice in music videos(Aubrey Jennifer \& $\mathrm{M}$. Frisby Cynthia, 2011). According to (Apuke, 2019), music videos exhibit erotic images containing sexualized portrayals reinforcing certain stereotypes. They possess sexualisation leading to indirect motives and consequences affecting the whole society. Additionally, this sexual objectification is mainly attributed to women. Women bodies especially their slim waists are highly visible in music videos. This factor is the cause of body attractiveness in music content (Swami, Antonakopoulos, Tovée, \& Furnham, 2006). Music videos are created to entertain the audience but their content is controversial(Hovater $\&$ Farris, 2020). According to a study conducted by (Force, 2018), entertainment media sensationalize and sexualize their content without considering the potential responsibilities of media The researcher concluded that music lyrics, videos and other related content contains higher amount of sexualized portrayals. (Wood, Julia, 1994) argued that the most prominent example of the sexualisation of women can be seen in music videos from all the genres. Provocative dance moves, actions and sometimes words make their portrayal sexually more attractive. However, in contemporary times sexual objectification is not limited to women anymore. The idea of female objectification in media was critical but now the balance is sustained by representing objectified portrayals of men (Lucas, 2018). Now the question is "if strong independent matrons raise their voices against the sexual objectification of women, do they enjoy sexual objectification of the opposite gender? As the male body is equally discussed and body parts are separately focused. Media objectify both women and men to attract and persuade their audience. Today, men are comparatively more objectified than women (Ali, 2019). In many cases, men complain that they have to oblige the content creators. Being a part of media they even do not own their own destiny (Cashmore Ellis, 2019). By keeping in view, the objectification, we argue that music videos provide a "fertile ground" of sexualized portrayals. They not only represent sex as a predominant theme (Chopyak, 1987) also reinforce stereotypes concerning love, sex and relationships. Furthermore, many studies assume that sexual objectification has increased over time (Dolan W Eric, 2019). Despite there are several studies concerning sexual objectification in music videos still we need to investigate this concern. Especially, maleobjectification in music videos is a less studied phenomenon. Also, the idea is media theorists and researchers tend to believe that exposure to certain media content also leads adoption of ideas and perceptions (Frazier \& others, 2013).Additionally, majority of these addressed female objectification in media content. Therefore, no direct predictions were made due to a lack of strong consistency in previous studies regarding male sexual objectification.

The major objectives of this study include: (i) Sexual objectification of men in music videos, (ii) Frequency of sexualized portrayals, (iii) Genres containing a comparatively higher number of sexualized portrayals and (iv) Discussing the social and psychological impacts of $t$ such portrayals

The following questionwas tested: 
Volume 8 Issue 2 February 2020

R1: Does male sexual objectification exist in music videos?

R2: Whether and to what extent male sexual objectification exist in music videos?

\section{Objectification in $\mathbf{a}^{\text {"Theoretical }}$ Perspective":}

Objectification is mainly representing a person as an objectification to use, lacks motion, personal freedom and owned by others. In this regard, from physical to nonphysical objectification, people accept it as a sociocultural practice. Men and women perceive objectification as a normal and daily routine occurrence. (Rodgers \& Hust, 2018). Therefore, the Feminist Perspective on Objectification by Martha Nussbaum is providing the conceptual background to this study. (Nussbaum, 1995) explained objectification under a theoretical perspective and associated it with treating someone "as an object who does not object in real". According to (Papadaki, 2012), the conceptual framework of Nussbaum's Objectification perspective is originally influenced by Immanuel Kant moral and philosophical views. However, many feminists consider objectification under just a single term "instrumentalization". To further elaborate the other major types of objectification, divided it into seven distant categories following features distinguishing the treatment of an individual as an object:

1. Instrumentality: Treating an individual as an object

2. Fungibility: Treating a person as interchangeable with other things

3. Denial of Autonomy: Treating an individual as lacking self-esteem and autonomy

4. Inertness: Treating a person as lacking activity

5. Ownership: Representing an individual as owned by another person

6. Violability: Treating a person as lacking integrity
7. Denial of Subjectivity: Treating an individual as lacking opinion, feelings and experiences

(Langton, 2009) added three more features into Nussbaum's concept of objectification:

8. Silencing: Treating an individual as they lack to speak (silent)

9. Reduction to Appearance: Treatment of an individual relying mainly upon how they look/ physical appearance

10. Reduction to Body: Identifying an individual with their body and body parts

By keeping in view the theoretical framework proposed by Nussbaum, analyzing sexual objectification in music videos is a whole different phenomenon. Visual images are coded for the desires of the audience leads to normalization of objectification culture among the spectators According to (Aorlotti, 2018).

\section{METHODOLOGY}

This study is exploratory in nature. The rese3archer stated two basic research questions to assess the existence of male objectification in the selected music content. After data gathering, the researcher also allocated codes to the responses (1=yes, $2=$ no).

\section{1: Sample of the Study}

To choose the sample, the researchers selected the songs from the top 100 of the Billboard Charts from January 2018 to December 2018 for two categories: Pop and Hip-hop. To construct the sampling frame, we grouped the sample by their respective genres. The researchers selected each song into the frame once. After the construction of two sample frames, the researchers used a simple random sampling technique and chose songs from each enlisted genre until we obtained a list of required videos from both selected genres. For the selection we had a certain criterion: (i), The video had to be among the top hundred music videos on Billboard Charts and, (ii) The video should be available on online platforms like YouTube, Daly motion and others and (iii), also we did not count 
Volume 8 Issue 2 February 2020

twice the videos got repeated in the charts. The sampling strategy resulted in total $n=97$ music videos ( $N=41$ for pop, $N=56$ for R\&B/hip hop). Additionally, we did not stratify the gender so we had a comparatively higher number of male artists $(\mathrm{n}=74$ or $76.2 \%)$ than the females $(n=23$ or $23.7 \%)$.

\subsection{Inter-coder Reliability:}

To validate the reliability of the coding technique, the researchers conducted Krippendorff's Alpha Inter-Coder Reliability analysis. With Krippendorff's Alpha value of .858 the researcher, therefore, affirmed that the coding technique is reliable.

\section{DATA ANALYSIS \& RESULTS}

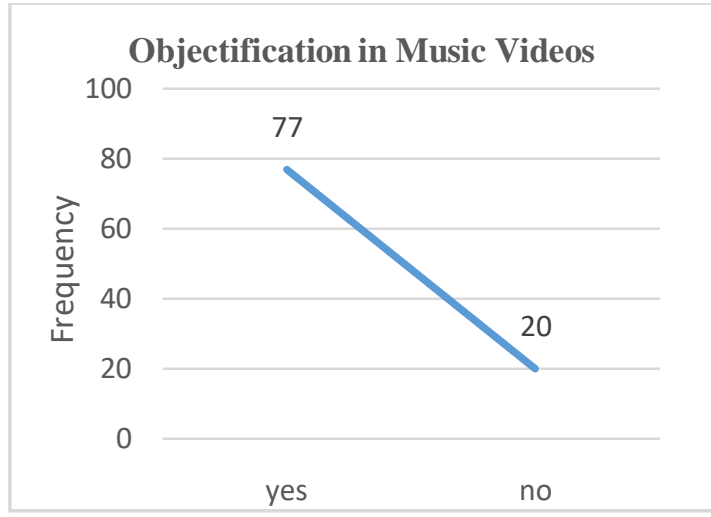

Figure 1 Descriptive Statistics for the Frequency of Male Objectified Portrayals

Figure one contains descriptive statistics for objectified portrayals of men. Findings revealed that $n=77$ or $79.3 \%$ of music videos $(M=1.21$, $S D=.407)$ contained sexually objectified portrayals of men. Likewise, cross-tabulation of data by music genre revealed that Hip-Hop music videos contain comparatively more objectified portrayals $(n=46$ $59.74 \%$ ). While the Pop music videos contained $n=$ 31 or $42.2 \%$ of male objectified portrayals in them. Also affirmed by (Ridgway Shannon, 2016) as she stated that men are represented half-naked to satisfy the female gaze. This idea is now a status quo and cultural norm where men please women. Some female artists are always under allegations for deliberately representing sexualized portrayals of men in their music videos

\section{Objectification by Music Genre}

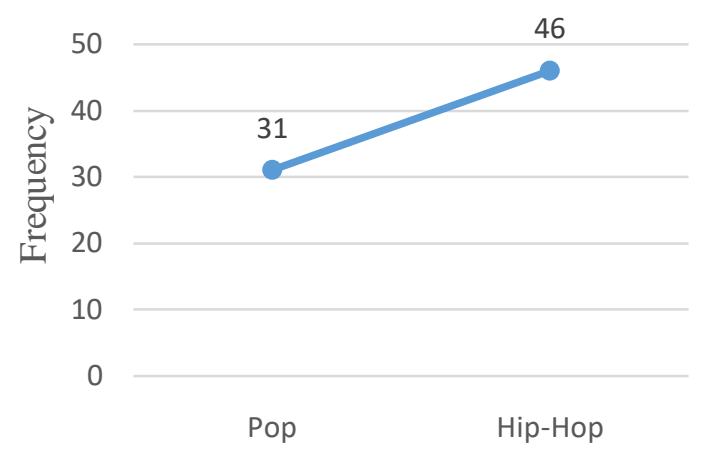

Figure 2 Descriptive Statistics for the Frequency of Male Objectified Portrayals in Both Genres

Furthermore, the researchers scrutinized each selected music videos under ten variables described by Martha Nusssbaum and Rae Langton. Table 1 below contains the Mean and Standard Deviation values of the data. Thus the cross-tabulation of data showed that:

Table 1 Mean and Standard Deviation of Objectification variables

\begin{tabular}{clcc}
\hline \multicolumn{4}{c}{ Male Objectification in Music Videos } \\
S/R & Variables & $M$ & $S D$ \\
\hline 1 & Instrumentality & 1.60 & .493 \\
2 & Denial of Subjectivity & 1.29 & .455 \\
3 & Denial of Autonomy & 1.33 & .473 \\
4 & Silencing & 1.32 & .462 \\
5 & Inertness & 1.29 & .472 \\
6 & Violability & 1.58 & .497 \\
7 & Fungibility & 1.29 & .455 \\
8 & Reduction to Appearance & 1.31 & .465 \\
9 & Reduction to Body & 1.37 & .486 \\
10 & Ownership & 1.31 & .465 \\
\hline
\end{tabular}

$N=39$ or $40.2 \%$ of videosare found having male models used by their female partners as an object for pleasure and entertainment. Touching their body, sexually alluring moves and facial expressions were found common among male models in the selected music videos.

Similarly, $n=65$ or $67.0 \%$ of videoswere found having no opinion, standing behind in the silent roles or dancing in the background. Male 
Volume 8 Issue 2 February 2020

models were mainly portrayed as expressionless individuals dancing on the beat and making dance moves.

Further, it was also revealed that $n=69$ or $71.1 \%$ of selected videoswere also unearthed containing men attributed to someone else. Serving women especially female singers was the most commonly found in the selected content.

When researcher scrutinized the occurrence of inertness and silencing in the selected content, it was found that many of men models represented as inert and in silent roles ( $n=66$ or $68.0 \%$ and $n=70$ or $72.2 \%$ respectively).They were dancing in the background or sitting silently without any movement.

$N=41$ or $42.3 \%$ of music content is also found portraying men as lacking integrity and being treated coarsely by their fellow male and female models, however, the level of violability was found comparatively higher in rap and hip-hop music videos.

\subsection{Chis-Square Analysis:}

Table 1 Inferential Statistics of Chi-square Analysis Concerning Music Videos and Male Objectification Case Processing Summary

\begin{tabular}{|c|c|c|c|c|c|c|}
\hline \multicolumn{7}{|c|}{ Case Processing Summary } \\
\hline & \multicolumn{6}{|c|}{ Cases } \\
\hline & \multicolumn{2}{|c|}{ Valid } & \multicolumn{2}{|c|}{ Missing } & \multicolumn{2}{|c|}{ Total } \\
\hline & $\mathrm{N}$ & Percent & $\mathrm{N}$ & Percent & $\mathrm{N}$ & Percent \\
\hline Music Genre * Objectification & 97 & $100.0 \%$ & 0 & $0.0 \%$ & 97 & $100.0 \%$ \\
\hline
\end{tabular}

\begin{tabular}{|c|c|c|c|c|c|}
\hline \multicolumn{6}{|c|}{ Chi-Square Tests } \\
\hline & Value & $\mathrm{df}$ & $\begin{array}{l}\text { Asymp. Sig. (2- } \\
\text { sided) }\end{array}$ & $\begin{array}{l}\text { Exact Sig. (2- } \\
\text { sided) }\end{array}$ & $\begin{array}{l}\text { Exact Sig. (1- } \\
\text { sided) }\end{array}$ \\
\hline Pearson Chi-Square & $.617^{\mathrm{a}}$ & 1 & .432 & & \\
\hline Continuity Correction $^{\mathrm{b}}$ & .283 & 1 & .595 & & \\
\hline Likelihood Ratio & .612 & 1 & .434 & & \\
\hline Fisher's Exact Test & & & & .457 & .296 \\
\hline Linear-by-Linear Association & .611 & 1 & .434 & & \\
\hline $\mathrm{N}$ of Valid Cases & 97 & & & & \\
\hline
\end{tabular}
videos were explicitly representing men lacking their freedom and tend to oblige others. $N=69$ or $71.1 \%$ of videosrevealed portraying men as redundant and interchangeable objects. Objects mainly included lavish lifestyle, cars, money and even bottles of wine.

In $n=67$ or $69.1 \% \%$ of videosmen were treated mainly the way they look and praised by women about their bodies. Additionally, many videos featured men having muscular bodies and focusing on women getting attracted by them.

$N=61$ or $62.9 \%$ of men found treated the way they look and body parts were mainly concentrated by the video originators. The camera was focusing more on the lower body parts and facial expressions were playing a distinctive role in objectifying them.

According to the findings, $n=67$ or $69.1 \%$ of menwere portrayed as if they are owned by someone else. Especially songs by female artists contained this element comparatively more. 
a. 0 cells $(0.0 \%)$ have expected count less than 5 . The minimum expected count is 8.45 .

b. Computed only for a $2 \times 2$ table

\begin{tabular}{|c|c|c|c|}
\hline \multicolumn{4}{|c|}{ Symmetric Measures } \\
\hline & & Value & Approx. Sig. \\
\hline \multirow{2}{*}{ Nominal by Nominal } & Phi & -.080 & .432 \\
\hline & Cramer's V & .080 & .432 \\
\hline $\mathrm{N}$ of Valid Cases & & 97 & \\
\hline
\end{tabular}

Although the researchers did not postulate any hypothetical assumption still it was important to conduct Chi-square analysis. The above-mentioned tables give a clear picture of any possible relationship between much videos and objectification of men. However, with the frequency calculation of data, we found that the majority of videos $(n=77$ or $79.3 \%$ ) contained male objectification still it is not much prevalent than that of women.

\section{DISCUSSION:}

Treating things as "objects" is not problematic but treating someone who is not a "thing" is considerably challenging. Most of the "inanimate" objects are subjected to our usage. We praise some of them for their beauty, unique features but still the lack of personal autonomy. Some are replaceable with other objects, some are breakable and thus "objects are objectified as objects" (Nussbaum, 1995). Similarly, (Nussbaum, 1995) also stated that objectification is a "pejorative" term that is used to identify some certain pattern of speaking and behaving. However, to criticize media content concerning advertisements, movies, music and others is widely used. Therefore, the research question of this study investigated the same phenomenon"Does male sexual objectification exist in music videos?" asthe basic intention was to scrutinize the phenomenon of male objectification prevailing in the music industry.As affirmed by (Aubrey \& M. Frisby, 2011), all media forms practice gender objectification but music videos are abnormally pre-eminent, the researchers preferred Billboard Charts of music videos to carefully examine the phenomenon. We, therefore, founda majority of music videoscontaining objectified representations well portrayed for "female gaze". Now the point is elaborating according to Nussbaum's conceptual background. As she stated that "Objectification is treating an object who is human in real" so $n=77$ or $79.3 \%$ of objectified portrayals we found a strong relevance.

Furthermore, the second research query"Whether and to what extent male sexual objectification exist in music videos?"led to estimating the frequency of male objectification in music videos. The results exhibited that the objectified portrayals are more common in Hip-hop music videos than pop songs videos.(Force, 2018) also authenticated this notion as he stated that are hundreds of songs released every year that objectify men and their body parts. Artists tend to objectify men on a large level. Songs like how many licks? I'm wild about that thing, Angel in a half-shirt, Nerdy boys, Nasty, 40 boys in 40 nights and others explicitly objectify men. Here what (Nussbaum, 1995) called it "scepticism" concerning others' attitudes and beliefs, was largely found. Also witnessed by (Neff, 2014) as she scrutinized the correlation between music videos and sexual objectification. Findings of her study revealed that the majority of music videos contain sexual objectification. However, the researcher also found that certain genres including Hip-hop and Rap involved comparatively higher levels of sexually objectified 
Volume 8 Issue 2 February 2020

portrayals. However, in Hip-hop music videos the objectification was mainly about lacking integrity of the individuals. Excessive fighting scenes and car racing were the major themes of these music videos.(Nussbaum, 1995) argued, objectification as violability and denial to subjectivity are two other most crucial forms of objectification. For example, "changes" by XXXTENTACION showing breaking cars with hammers having masked faces. Similarly, "Powerglide" by Rae Sremmurd, Swae Lee, Slim Jxmmift Juicy J showing car race with a male model rashly driving the car. "Havana" by Camila Cabello was another major song starting with a "sex" scene when Camila encounters her boyfriend being busy with another woman. However, objectification was not necessarily about focusing on body or body parts as in many cases male models were featured as servants, statues and in silent roles. As for instance, songs like One Kiss by DuaLipa contained Calvin Harris holding a tray and serving juice to the vocalist. Here we can attribute it with "slavery" as stated by (Nussbaum, 1995) it is a type of ownership entailing denial of autonomy who is owned by others. A human who is treated as a slave here tends to feel like an object which can be sold. Therefore, we found pop songs containing higher levels of objectification attributed to denial of autonomy, silencing, reduction to body and reduction to appearances. Hence, Objectification containing songs are a source of "fresh and pleasurable addition in pop culture and media industry. Music videos often objectify muscular men wearing nothing but only an undergarment while washing cars and bikes. If men objectify women then objectifying men by women is not an appropriate way to retaliate (Kovarik, 2014).

According to (Agliata \& Tantleff-Dunn, 2004), besides the curse of women objectification in the media, male objectification which has now become a critical concern. Poisonous sexualized portrayals of men do exist in media and they are unpropitiously exploiting the society. However, it is acceptable for men to appear as sexually pleasurable and satisfying "objects". Although this objectification is less than that of female objectification, still such portrayals are precarious for society( Daubny, 2015). Although, sexual objectification of men is not as same as of women still it is not even justifiable. It does not make any point if someone objectifies others as this is treating others less than humans (Kovarik, 2014).

\section{1: Effects of Male Objectification:}

Effects of sexualized portrayals bring adverse outcomes. Exploiting ones dignity by resorting sexual objectification brings negative outcomes (Vaes, Loughnan, \& Puvia, 2014). They not only lead towards besides other impacts they also become a reason of self-objectification in men. In this context, many studies also witnessed both the potential effects of male objectification. (Hargreaves \& Tiggemann, 2004) assessed the impacts of exposure to objectified body portrayals. Results revealed that After exposure to sexualized portrayals, both girls and boys were having negative moods and psychological distress. Additionally, objectified portrayals also result in higher tevels of body dissatisfaction among individuals. Also affirmed by $(\mathrm{C}, 2007)$ as he stated that exposure to sexually objectified portrayals of men has adverse psychological effects. Body discontent and psychic unrest are found among men. This dissatisfaction can cause low selfesteem, depression, stress and even many other detrimental outcomes (Franz, DiLillo, \& Gervais, 2016). In many cases, sexual objectification of men also hinders wellbeing and validate sexist stances (Rollero, 2013). According to (Heflick, Goldenberg, Cooper, \& Puvia, 2011), psychologists need to oversee and help the people concerning the expulsion of sexually objectified portrayals of individuals.

Besides the psychological impacts of sexual objectification, there are certain other consequences caused by sexual objectification of men. According to (Attenborough, 2011) with sexualisation in media gender stereotyping is also among one of the adverse outcomes caused by objectification. Image of sexy men and women is a routine practice as "we are all objectified now". He further stated that rigid gender norms and stereotypes still loom in our society. As objectification leads to the coating of certain stereotypical parables about gender roles in our society. Hostility towards the opposite gender is another consequence caused by sexual objectification in media content. (C, 2007). Therefore, it is suggested that objectification should be addressed and eradicated from media practices. objectifying men along with women is 
Volume 8 Issue 2 February 2020

not a victory rather demoralization and humiliation (Wade, 2013).

\section{CONCLUSION}

This study analyzed the persisting sexualized portrayals of men in music videos under the objectification perspective proposed by (Nussbaum, 1995). Also, the extent to which videos from particular genres contain male objectified portrayals.By linking this study with Objectification theory, we intended to provide a strong background to this study. Also, despite the prevailing male objectification, there is no particular theoretical background supporting this phenomenon. Here we assume that objectification is dehumanization and anyone facing this dehumanization is considered a "victim" regardless of their gender identity. According to (Vaes et al., 2014), dehumanization and humiliation are a primary factor concerning objectification. This concept can be defined by using both philosophical and psychological perspectives.

Likewise, (Munoz, 2011) argued that due to convenient access and exposure to music content, people experience to see various type of music videos. These videos largely contain sexually objectified portrayals of men and women Findings also validated the notion of sexual objectification of males in featured music content. Results found a large number of objectified portrayals in music content. Further, the researchers briefly discussed the studies concerning the impacts of sexual portrayals of men. Altogether, linking male sexual objectification with potential psychological and social impacts, we can conclude that objectification is a humiliation. Aimed at exposing one as an object to "use, harm or lacking personal freedom and others", adversely affects the sovereignty and values of the whole society. Although the female objectification is highly detrimental, male sexualisation is also of greater concern. Moreover, those who protest against women objectification, fancy male objectification as a normal social practice. This is because sexism has rooted so deeply that it is not a considerable issue for us anymore. Our inclination towards nudity and the media's role to gratify our demands lead to the sexualisation of individuals. Many strong women tend to objectify men. For most of them, male objectification should also be taken as a practice just like female objectification (Peter Lucas, 2018).Also, men do not bother about male objectification because they have superiority and they are acceptable in any form. Objectified portrayals of men are not a problem or serious concern as it would not affect their power and appearance in any sense (Amber Fraley, 2018). By keeping in mind the consequences of prevalent male objectification, the researchers suggest that it should be prohibited. Like female objectification, male objectification is also harmful in many ways. Therefore, being women, if we want equality, we should fight for human rights and male objectification is a human rights violation too (Wade, 2013).

\subsection{LIMITATIONS RECOMMENDATIONS}

This study is conducted in a limited period with finite resources. Although the effects of male objectification are widely discussed still male objectification in music content is not a muchstudied phenomenon. For this reason, literature discussing male objectification is cited from websites and blogs which is another limitation of this study. Therefore, the researcher declared and validated the research hypothesis as basic intent was to conduct a study to authenticate the respective phenomenon. Also, the researchers recommend more investigations to highlight the male objectification in different types of media content. We need more data regarding this topic so that we may raise these issues on an international level.

\section{Ethical Approval}

All procedures performed in studies involving human participants were in accordance with the ethical standards of the institutional and/or national research committee and with the 1964 Helsinki declaration and its later amendments or comparable ethical standards.

\section{Funding:}

This study has not received any funding.

\section{Conflicts of Interest:}

None 
Volume 8 Issue 2 February 2020

\section{REFERENCES}

Agliata, D., \& Tantleff-Dunn, S. (2004). The impact of media exposure on males' body image. Journal of Social and Clinical Psychology, 23(1), 7-22. https://doi.org/10.1521/jscp.23.1.7.26988

Ali, S. (2019). (1) (PDF) Citation: Ali S. Women Objectification and Advertising: An Analysis of Sexually Objectified Portrayal of Women in Television Advertising in Pakistan. Retrieved from https://www.researchgate.net/publication/334 537087_Citation_Ali_S_Women_Objectifica tion_and_Advertising_An_Analysis_of_Sexu ally_Objectified_Portrayal_of_Women_in_T elevision_Advertising_in_Pakistan

Amber Fraley. (2018). Let's Objectify Men Amber Fraley - Medium. Retrieved January 26, 2020, from https://medium.com/@AmberBobamber_432 68/lets-objectify-men-a593fdf3d4db

Aorlotti. (2018). Gaze and Gender in Music Videos Using Charli XCX's Boys - Studies in Visual Cultures - ENG 705. Retrieved January 27, 2020, https://visualculture.blog.ryerson.ca/gaze and-gender-in-music-videos/

Attenborough, F. T. (2011). Complicating the sexualization thesis: The media, gender and 'sci-candy.' Discourse \& Society, 22(6), 659-676. https://doi.org/10.1177/0957926511411693

Aubrey Jennifer, \& M. Frisby Cynthia. (2011). (PDF) Sexual Objectification in Music Videos: A Content Analysis Comparing Gender and Genre | Cyndi Frisby Academia.edu. Retrieved January 27, 2020, from https://www.academia.edu/27320892/Sexual _Objectification_in_Music_Videos_A_Conte nt_Analysis_Comparing_Gender_and_Genre

Bjornberg, A. L. F. (2011). Structural relationships of music and images in music video1. 13(1), 51-74.

Brown, W. J., \& Singhal, A. (1993). Entertainmenteducation media: An opportunity for enhancing Japan's leadership role in third world development. Review Literature And Arts Of The Americas, (15), 81-102.

C, J. C. (2007). Handbook of Gender Research in Psychology: Volume 2: Gender Research in ... - Google Books. Retrieved January 26, 2020, from https://books.google.com.pk/books?id=prTnlt $\mathrm{nNbC} 4 \mathrm{C} \& \mathrm{pg}=\mathrm{PA} 666 \& \mathrm{lpg}=\mathrm{PA} 666 \& \mathrm{dq}=\mathrm{Mc}$ Creary,+Mills+and+Johnson+(2007),+effects + of + sexually+objectified+portraysl\&source $=$ bl\&ots=MndTNNalR $1 \&$ sig $=$ ACfU3U2 $33 \mathrm{sm}$ HznMaUgamr7BdAHIcx2_LYg\&hl=en\&sa= X\&ved=2ahUKEwitxcn2iqHnAhXIQ0EAH

Casey Kovarik. (2014). Second Take: Objectification in Jennifer Lopez's music video perpetuates issue | Daily Bruin. Retrieved January 26, 2020, from https://dailybruin.com/2014/06/29/secondtake-objectification-in-jennifer-lopezs-musicvideo-perpetuates-issue/

Cashmore Ellis. (2019). Why the Objectification of Men Is Different. Retrieved January 27, 2020, from https://www.fairobserver.com/worldnews/male-sexual-objectification-womenculture-news-15421/

Celasin, C. (2013). The Effects of Musical Elements in Mass Media and Internet on the Social Development of Children and Adolescents Music and ( social, anthropological, aesthetical, etc .) components of it in life have been a large tool for socio-cultural studies. Educa. 2(July), 7989.

Chopyak, J. D. (1987). The Role of Music in Mass Media, Public Education and the Formation of a Malaysian National Culture. Ethnomusicology, 31(3), 431. https://doi.org/10.2307/851665

Dinu, E. L. (2016). Aspects of media "massentertainment" in contemporary Romania. Calitatea Vietii, 27(4), 294-303.

Dolan W Eric. (2019). Female artists increasingly portrayed with sexually suggestive movements in popular music videos. Retrieved January 27, 2020, from https://www.psypost.org/2019/04/femaleartists-increasingly-portrayed-with-sexuallysuggestive-movements-in-popular-musicvideos-53478

Force, T. (2018). Sexualization of Popular Music Sexualization of Popular Music.

Franz, M. R., DiLillo, D., \& Gervais, S. J. (2016). Sexual Objectification and Sexual Assault: Do Self-Objectification and Sexual Assertiveness Account for the Link? 
Volume 8 Issue 2 February 2020

Psychology of Violence, 6(2), 262-270. https://doi.org/10.1037/vio0000015

Frazier, E., \& others. (2013). Girls, Girls, Girls: Analyzing Race and Sexuality Portrayal in Music Videos. Being a Master s Project, Media Studies, Department of Communication, University of Florida.

Goldstein, J. H. (2017). Applied Entertainment: Positive Uses of Entertainment Media. In Handbook of Digital Games and Entertainment Technologies (pp. 12471269). https://doi.org/10.1007/978-981-456050-4_9

Hargreaves, D. A., \& Tiggemann, M. (2004). Idealized media images and adolescent body image: "Comparing" boys and girls. Body Image, 1(4), 351-361. https://doi.org/10.1016/j.bodyim.2004.10.002

Heflick, N. A., Goldenberg, J. L., Cooper, D. P., \& Puvia, E. (2011). From women to objects: Appearance focus, target gender, and perceptions of warmth, morality and competence. Journal of Experimental Social Psychology, 47(3), 572-581. https://doi.org/10.1016/j.jesp.2010.12.020

Hovater, R. S., \& Farris, D. N. (2020). Back That Sexism Up: An Analysis of the Representation of Women's Bodies in Music Videos. In Gender, Sexuality and Race in the Digital Age (pp. 75-97). https://doi.org/10.1007/978-3-030-29855-5_5

Karsay, K., \& Matthes, J. (2016). Sexually Objectifying Pop Music Videos, Young Women's Self-Objectification, and Selective Exposure. Communication Research, 009365021666143.

https://doi.org/10.1177/0093650216661434

Langton, R. (2009). Sexual Solipsism: Philosophical Essays on Pornography and Objectification.

Martin Daubny. (2015). Men are now objectified more than women - Telegraph. Retrieved January 26, 2020, from https://www.telegraph.co.uk/men/thinkingman/11395576/Men-are-now-objectifiedmore-than-women.html

Munoz, L. (2011). Influence of Rap and Hip-hop Lyrics on Male Body Image and Attitudes Toward Women. McNair Poster Presentations. Retrieved from https://digitalscholarship.unlv.edu/mcnair_po sters $/ 6$
Neff, S. (2014). Sexism across musical genres: A comparison. Scholar Works at WMU, 1-37.

Nussbaum, M. C. (1995). Objectification. Philosophy \& Public Affairs, Vol. 24, pp. 249-291. https://doi.org/10.2307/2961930

Oberiri Destiny Apuke. (2019). (1) (PDF) Portrayal and Objectification of Women in Music Videos: A Review of Existing Studies. Retrieved January 27, 2020, from https://www.researchgate.net/publication/335 097114_Portrayal_and_Objectification_of_W omen_in_Music_Videos_A_Review_of_Exis ting_Studies

Papadaki, E. (2012). Understanding objectification: Is there special wrongness involved in treating human beings instrumentally? Prolegomena, 11(1), 5-24.

Peter Lucas. (2018). This is why the sexual objectification of men on TV isn't just a bit of fun The Independent. Retrieved January 26, 2020, from https://www.independent.co.uk/voices/bodyg uard-poldark-male-objectification-loveisland-tv-feminism-a 8543096.html

Rager, D., \& Rager, D. (2008). EngagedScholarship@CSU The Role of Music in Society Past, Present and Future. Retrieved from https://engagedscholarship.csuohio.edu/clmus ic_facpubhttps://engagedscholarship.csuohio. edu/clmusic_facpub/3

Ridgway Shannon. (2016). Can Men Be Objectified By Women? - The Establishment - Medium. Retrieved January 28, 2020, from https://medium.com/the-establishment/canmen-be-objectified-by-women$783 \mathrm{~d} 7776 \mathrm{a} 59 \mathrm{~b}$

Rodgers, K. B., \& Hust, S. J. T. (2018). Sexual objectification in music videos and acceptance of potentially offensive sexual behaviours. Psychology of Popular Media Culture, 7(4), 413-428. https://doi.org/10.1037/ppm0000142

Rollero, C. (2013). Hombres y Mujeres Frente a la cosificación: Los Efectos de los Modelos mediáticos Sobre el bienestar, la autoestima y el sexismo ambivalente. Revista de Psicologia Social, 28(3), 373-382. https://doi.org/10.1174/02134741380771916 6

Silver, D., Lee, M., \& Childress, C. C. (2016). Genre Complexes in Popular Music. PLoS 
Volume 8 Issue 2 February 2020

ONE, 11(5), 1-23.

https://doi.org/10.1371/journal.pone.0155471

Starej, F. (2017). History of music videos in the media. (September), 1-25.

Swami, V., Antonakopoulos, N., Tovée, M. J., \& Furnham, A. (2006). A critical test of the waist-to-hip ratio hypothesis of women's physical attractiveness in Britain and Greece. Sex Roles, 54(3-4), 201-211. https://doi.org/10.1007/s11199-006-9338-3

Vaes, J., Loughnan, S., \& Puvia, E. (2014). The inhuman body: When sexual objectification becomes dehumanizing. - PsycNET. Retrieved January 28, 2020, from https://psycnet.apa.org/record/2013-40652012

Vernallis, C. (1998). The aesthetics of music video: an analysis of Madonna's 'Cherish.' Popular Music, $17(2)$, 153-185. https://doi.org/10.1017/s0261143000000581

Wade Lisa. (2013). Does the Rise of Men's Sexual Objectification = Equality? - Sociological Images. Retrieved January 26, 2020, from https://thesocietypages.org/socimages/2013/1 2/12/hunkvertising-is-the-rise-of-menssexual-objectification-equality/

Wood, Julia, T. (1994). Gendered Media: The Influence of Media on Views of Gender. Gendered Lives: Communication, Gender and Culture, 231-244. Retrieved from https://www1.udel.edu/comm245/readings/G enderedMedia.pdf

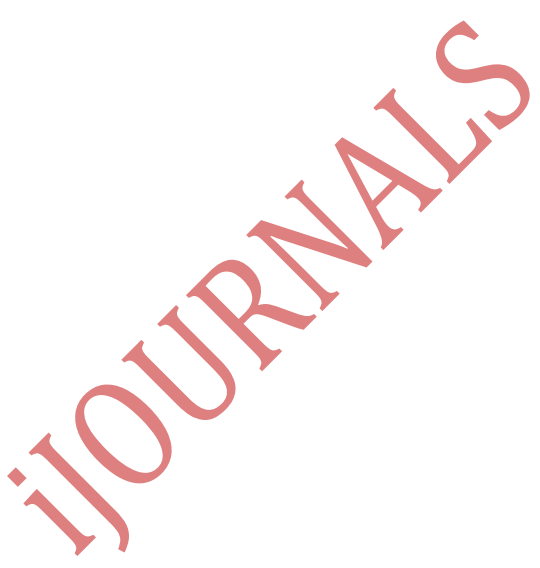

